\title{
Role of leadership in the management of corporate knowledge
}

\author{
J.A. Kok \\ Department of Information Studies \\ Rand Afrikaans University \\ jako@lw.rau.ac.za
}

\section{Contents}

1. Introduction

2. What is knowledge leadership?

3. Role of the knowledge leader

4. Contribution of the chief executive officer

5. Leadership at all levels

6. Vibrant knowledge team

7. Frameworks for knowledge management

8. Conclusion

9. References

\section{Introduction}

According to Amidon (2000) modern leaders do not fear the speed of change; rather they embrace an agenda of learning. They know that effective management is not a matter of having the most knowledge; but knowing how to use it. It is not enough to know modern management concepts, but how they get implemented is equally important. Therefore, leadership is more of an art than a science.

Businesses are well advised to manage knowledge as effectively as possible and they are doing this by drawing on the abilities, insight and skills of a new category of professionals the knowledge officer - to increase organizational competitiveness and to enhance the productivity of all employees (Barclay 2003). According to Davenport (1996), the chief knowledge officer captures and leverages structured knowledge with information technology as a key enabler. Companies need people who are able to extract knowledge from those who have it, reorder it into a format anyone can use and update and edit that knowledge as required over time. The most likely organizations to support knowledge management, organizational learning and formal chief knowledge officer positions are companies that value learning and knowledge as critical to their business strategies, and not just as 'nice things to do' (Bonner 2000).

Thus the role of the knowledge leader is deeper than what the chief executive officer (CEO) is often expected to be and broader than the chief information officer (CIO) wants to be or 
has time to be. Hence the qualities of the knowledge leader are an unusual and perhaps a rare mix.

The purpose of this article is then to discuss the role of, and competencies needed by the knowledge leader.

\section{What is knowledge leadership?}

Arthur Anderson, in association with the American Productivity and Quality Center (APQC), has developed a diagnostic tool to help organizations benchmark their knowledge management processes. The tool includes an Organization Knowledge Management Model that covers 24 emerging knowledge management practices grouped into these four categories of enablers:

- Leadership

- Technology

- Culture

- Measurement.

The model attributes good knowledge leadership to four essential properties.

- Management of organizational knowledge is recognised as being central to the organizational strategy.

- The organization grasps the potential of its knowledge resource and develops strategies for marketing it.

- The organization uses knowledge and learning to support existing core competencies and to create new ones.

- Individuals are appointed, evaluated and rewarded on the basis of their contribution to developing organizational knowledge.

The following factors are the essence of knowledge leadership and are discussed below:

- A knowledge leader

- The support of the chief executive

- Leadership at all levels

- A vibrant knowledge team

- A framework for action.

\section{Role of the knowledge leader}

The appointment of a knowledge leader is an indication that the importance of knowledge in the future prosperity of an organization is recognised. Earl (1999) states that the role of the knowledge leader is so immature that there are no job specifications available. Many knowledge leaders work out their own agenda because their mission is not clear. Skyrme and Amidon (1997:73) identified the following roles as critical to the success of a knowledge leader:

\subsection{Promote the knowledge agenda}

\subsubsection{Support education and learning}


The knowledge leader must be an advocate of knowledge and learning. The knowledge leader is the designer, implementer and overseer of an organization's knowledge infrastructure, including its libraries, knowledge bases, human resources, computer knowledge networks, research centres and academic relationships (Davenport 1994).

The knowledge leader has a huge responsibility for educating both leadership and employees about knowledge management and its benefits. This includes defining roles, skill sets and career opportunities of knowledge workers, developing a strategy to facilitate training and education of knowledge workers and developing learning centres.

Earl (1999) suggests that knowledge leaders need to connect to any management education and organizational development initiatives that increase the emphasis on and enhance the capacities for knowledge creation. Examples include experience-sharing events and experience-shaping projects and assignments for fast-track managers and instilling career development programmes with broad and deep knowledge acquisition. Knowledge leaders therefore need to teach information seekers how to ask better and smarter questions (Duffy 1998)

\subsection{Develop the infrastructure}

\subsubsection{Promote 'best practices and processes'}

The knowledge leader has to provide the infrastructure and incentives for knowledge reuse and innovation and provide a means to benchmark the performance of individuals and teams.

\subsubsection{Create a knowledge sharing culture}

It is the responsibility of the knowledge leader to promote an organizational culture that facilitates tacit and explicit knowledge sharing and organizational learning. To accomplish this, the knowledge leader has to foster a cultural change. One knowledge leader explains it as follows: 'Unless I can persuade people that KM is not just for the benefit of other people, I haven't got much hope or persuading them to buy into it. They have to believe there's something in it for them to buy into it. They have to believe there's something in it for them and that I care about that as much as they do. Otherwise it just comes across as the latest form of cynical manipulation' (Earl 1999).

Earl (1999) suggests that knowledge management is 20\% technology and $80 \%$ cultural change, and therefore knowledge leaders are eclectic change agents. Given the important role that knowledge plays in corporate strategies, long-term changes are needed in organizational cultures and individual behaviour relative to knowledge (Davenport 1994).

Knowledge leaders are relationship builders as the fundamental issues are people, culture, roles, behaviours and the business processes in an organization (Bonner 2000).

\subsubsection{Advocate communities of practice}

It is important that the knowledge leader is the advocator of cross-organizational communities of practice. They have to form relationships with related leaders, that is, in human resources (HR), organizational learning, information technology (IT) and librarians. Often, knowledge leaders look for people who are excited about a particular knowledge management idea or project and thus have identified where improvement is possible and are likely to want to try something new. These people become knowledge champions. Knowledge leaders also seek to identify senior executives who are enthused by knowledge management, who identify with the concept and make public statements about it. These are potential knowledge sponsors who will invest in and support knowledge management projects. The knowledge leader will also need allies in implementation typically information system (IS) executives and HR professionals who become knowledge partners (Earl 1999). 
Davenport (1996) gives the example of John Peetz, partner and knowledge leader of Ernst and Young, who has set up a three part organizational infrastructure for knowledge management with knowledge councils for international US and individual business units operations. In the consulting unit, the company has set up knowledge networks for each key practice area. Although the creation and maintenance of such infrastructure takes time and effort, the labour is necessary if the knowledge management is to become institutionalized.

Knowledge workers need to identify each other and develop an occupational community (Davenport 1996). In addition, the base of knowledge does not always reside inside the firm. Creativity and new ideas often came from allied partners, customers and even competitors (Amidon 2000).

\subsubsection{Use incentives and rewards}

The knowledge leader has to develop incentives to encourage knowledge sharing, acknowledge that 'one size does not fit all' and recognise and promote knowledge contributors who share knowledge across the enterprise.

\subsubsection{Provide tools and technology}

The task of KM involves workstations, networks, databases, search engines, word processing and desktop publishing tools (Davenport 1994). The knowledge leader plays a leading role in the design and implementation of a company's knowledge architectures (Davenport 1996) and the knowledge leader is more likely to view technology as only an enabler for an effective knowledge management system (Bonner 2000).

\subsection{Connect, co-ordinate and communicate}

The knowledge leader is responsible for the development of a knowledge management budget and is an advocate for keeping knowledge resources available for those who are eager to experiment with knowledge management in their respective occupations. Although knowledge budgets and staff are considerably moderate, expenditure may grow in the future. In the meantime, high-level sponsorship is essential and many knowledge management projects or investments are corporately funded if they apply enterprise wide and locally funded if at the business unit or individual level.

The knowledge leader is also the primary liaison between external providers of information and knowledge. This is a major expense for many companies, therefore efficient and effective management is important. The knowledge leader provides critical input into the creation of knowledge and uses processes, such as product development, that already exist within the company (Davenport 1994).

\subsection{Development of the 'big picture'}

\subsubsection{Provide leadership and strategy}

The knowledge leader is a visionary; he or she is able to see the big picture that the CEO has in mind but is also able to translate it into action, to think of new ways of doing things and yet focus on deliverable results (Earl 1999). The knowledge leader has to create and sell the knowledge management vision and has a responsibility to help the CEO to drive the organization in the desired direction. He has to communicate commitment to and strategy for knowledge management to both stakeholders and players.

The knowledge leader has to 'light fires and implement pilot products and projects using tools and technologies and act as a liaison with other agencies and industry partners to facilitate the sharing of world-class knowledge practices. In addition, he or she acts as a transformation agent by changing industrial age thinking to information age thinking. As the 
leader develops strategies to make tacit knowledge explicit, he or she provides guidance and policy on processes to institutionalise knowledge management practices.

The knowledge leader is also a consultant who brings in ideas, seeds them, listens to other people's ideas and backs them if they make sense and fit the knowledge vision (Earl 1999).

Davenport (1996) suggests that the knowledge leader has to determine how better management of knowledge will help a company make or save money and document that economic impact. The primary success factor of being a knowledge leader is being a businessperson first and understanding how to drive through a strategic initiative. The knowledge leader must be able to communicate, think strategically and talk the language of executives (Denner 2000).

\subsubsection{Measure outcomes}

The knowledge leader needs to contribute to company goals, or the bottom line. He needs to evaluate the effectiveness of knowledge management projects and benchmark with other organizations, both public and private. He has to ensure that intellectual capital is converted to structural capital, thus reducing operating costs and development time for products and services.

Earl (1999) suggests that, as a technologist, the knowledge leader has to understand which technologies can contribute to capturing, storing, exploring and sharing knowledge. The knowledge leader has to be sufficiently informed about technology to evaluate what works, to judge when to adopt a technology, to appreciate the opportunities enabled and to assess any demanding implementation issues. Sometimes, the knowledge leader is the sponsor of the IT project and nearly always has to work with the CIO or senior IS executive. The knowledge leader must have the confidence to have credible discussions with technology partners, which were more likely to come from past involvement with IT projects than from formal IT training. Technology capability is not optional, as a first initiative often is to create knowledge directories, develope knowledge sharing groupware or build an intranet.

\subsection{Competencies needed by the knowledge leader}

Duffy (1998) in his article 'What does it take to be a successful knowledge leader?' points out that several studies have been conducted to determine whether someone is well suited to lead an organization's knowledge management efforts.

The information management consultancy, TFPL (Skyrme and Amidon 1997:345), carried out a research project and compiled a useful framework. In essence the researchers distinguish between the four competencies listed in Table 1. Skills, experience, attributes and behaviour are needed to be a knowledge leader.

\begin{tabular}{|c|c|c|c|}
\hline Skills & Experience & Attributes & Behaviour \\
\hline $\begin{array}{l}\text { - } \text { Information } \\
\text { skills } \\
\text { - Communication } \\
\text { skills } \\
\text { - Skills transfer } \\
\text { - Value adding }\end{array}$ & $\begin{array}{l}\text { - } \text { Information } \\
\text { technology } \\
\text { - } \text { Communication } \\
\text { - General } \\
\text { management } \\
\text { - Information } \\
\text { management } \\
\text { - Business } \\
\text { strategy }\end{array}$ & $\begin{array}{l}\text { - Business } \\
\text { focus } \\
\text { - Team } \\
\text { approach } \\
\text { - Values } \\
\text { ethos } \\
\text { - People } \\
\text { focus } \\
\text { - Leadership }\end{array}$ & $\begin{array}{l}\text { - Confidence } \\
\text { - Influencing } \\
\text { - Sharing } \\
\text { - Skills } \\
\text { transfer } \\
\text { - Risk taking } \\
\text { - Identify } \\
\quad \text { with } \\
\text { business }\end{array}$ \\
\hline
\end{tabular}




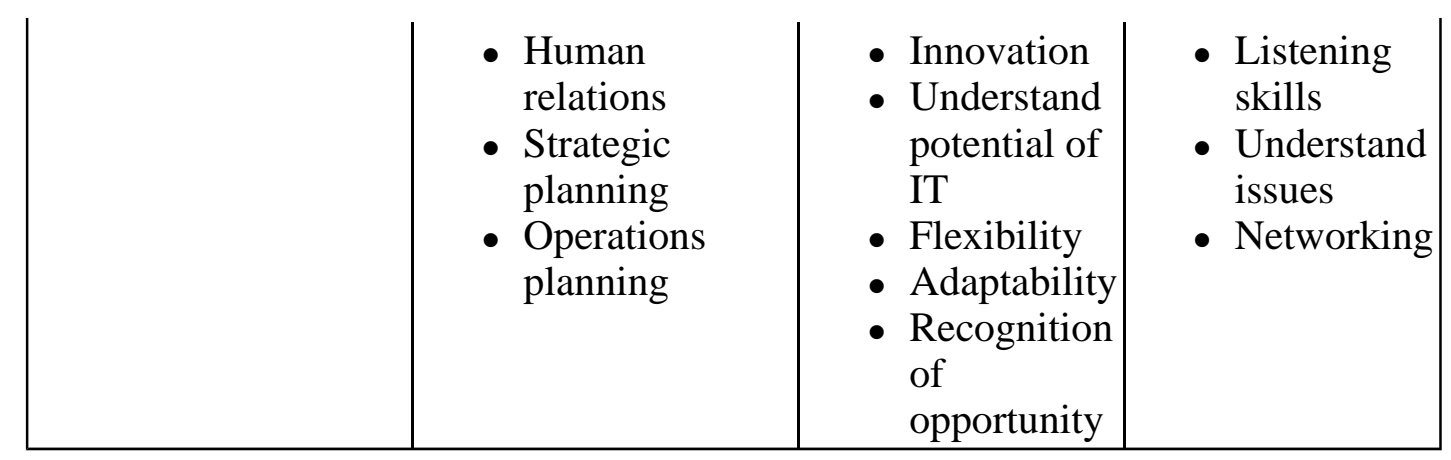

top

\section{Contribution of the chief executive officer (CEO)}

As knowledge becomes more important in many organizations, the role of the CEO will change. Top management's initial emphasis on structure leads to problems and to a shift in emphasis towards changing behaviours and developing relationships. Therefore a good relationship between the CEO and knowledge leader is very important. The role of the CEO can vary from one of passive support to active stimulation and to knowledge leadership, where the CEO personally takes a leading role in making knowledge initiatives happen. The endorsement of the knowledge management initiatives by the CEO certainly helps and makes the knowledge champions more enthusiastic about the process (Skyrme and Amidon 1997:79).

\section{Leadership at all levels}

The process of diffusion and acceptance of new ideas about knowledge that is articulated into a new knowledge management programme is far more complex and involves all levels of management in the company. According to Nonaka and Takeuchi (1995), top management provides the vision, the frontline looks at reality, and middle management closes the gap between dream and reality.

\section{Vibrant knowledge team}

Knowledge leaders don't work alone. Typically the knowledge team is a small core of fulltime staff with a network that extends into other parts of the organization. This team includes people from several backgrounds, such as sales, marketing and information management. Expertise includes knowledge about culture, behaviours and rewards. The main role of team members is that of facilitators of knowledge sharing and they act as a focal point for knowledge activities (Skyrme and Amidon 1997:89).

top

\section{Frameworks for knowledge management}

One of the roles of knowledge leaders is to oversee the development and implementation of a comprehensive knowledge management architecture. Some examples are the following: 


\subsection{Wiig's knowledge management framework}

Karl Wiig said that the hands-on tools and approaches that are required to support knowledge management programmes should be assembled into a coherent framework. This is necessary to provide a working overview of the available knowledge, and to determine which methods and perspectives are appropriate for different purposes and situations (Skyrme and Amidon 1997:90). This framework is illustrated by visualizing knowledge management as being supported by three pillars of methods and approaches that rest on a broad foundation. The three pillars are the following (Figure 1):

- Exploring knowledge and its adequacy. Here knowledge and its related activities are analysed, surveyed, elicited, codified, organized and categorized.

- Establishing the value of the knowledge. An appraisal and evaluation of the value of knowledge and its related actions are done.

- Managing knowledge explicitly. In this phase, knowledge-related activities are synthesized. It covers the handling, use and control of knowledge. Lastly it encompasses leveraging, distribution and automation of knowledge.

Figure 1 Three pillars of knowledge management (Source: Skyrme and Amidon 1997:90)

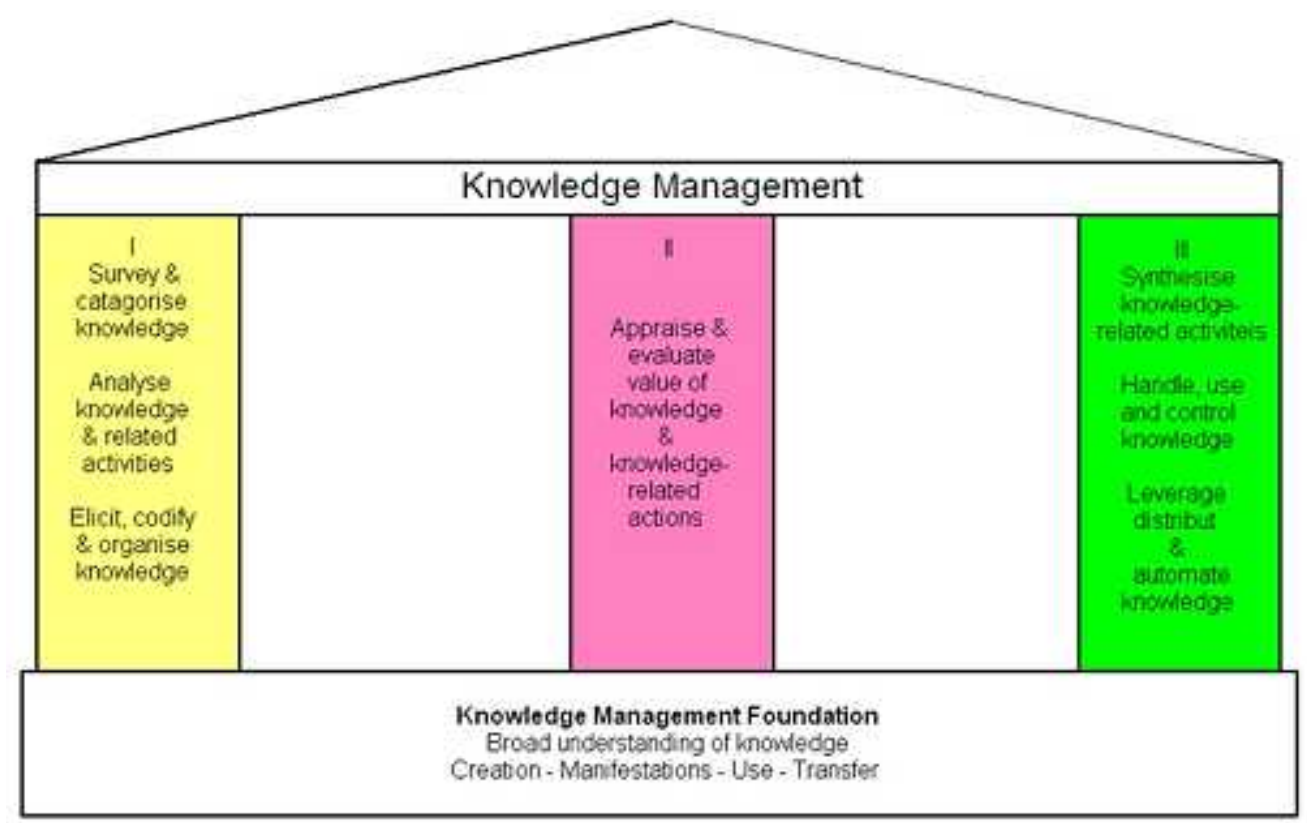

\subsection{Skandia Navigator}

Skandia AFS, a financial services company based in Sweden, has taken the lead in developing measures of intellectual capital as a practical knowledge management tool. The Skandia Navigator incorporates measures in several dimensions. It is used as a model to drive sustained business development and to ensure that management actions and behaviours are consistent with renewal and development as well as financial performance. The Navigator is designed to provide a balanced picture of the financial and intellectual capital. The focus on financial results, capital, and monetary flows is complemented by a description of intellectual capital and its development. Indicators that specify both the level and change are highlighted (Rubin 1998). The Navigator provides what Skandia describes as a 'taxonomy of intellectual capital reporting', where intellectual capital is the hidden value of an organization. Described as both a metaphor and tool, the Navigator is a management and reporting model that helps managers visualize and develop measures that reflect the intangible assets (Skyrme and Amidon 1997:143). 
Although the Skandia Navigator is portrayed as a management and reporting model, it is used to guide management actions and work processes in the development of intellectual capital and acts as the guidance framework for knowledge management. Here the metaphor is one of a house. Its roof represents the financial capital without which the company could not survive. The process and customer focuses are presented by the walls. The base represents the renewal focus - the foundations for future long-term prosperity. The interior is the soul of the house - Skandia employees.

The Navigator started when Skandia focused on drivers for growth and renewal. In many companies, intellectual capital is reflected in the difference between a company's market value and book value, which is for many companies in Sweden a factor of 10 or more. This gap in intellectual asset is a combination of human and structural capital. Assets that don't normally get reported in company annual reports and accounts include employee competence, work processes, customer lists and so on. This, according to Leif Edvinson, the Corporate Director of Intellectual Capital at Skandia, gives a distorted view of the true value of a company, particularly a knowledge-intensive one such as Skandia, where value will be found in traditionally unreported factors such as customer relationship and fund management expertise. Edvinson developed a new method of reporting. His goal was to 'identify' the hidden unreported value in the company's assets, to focus the attention of management on their development:

'We operate in ten countries. We looked at the hidden values that we had. We found we had trademarks, concessions, customer databases, distribution systems, fund management systems, IT systems, core competencies, key persons, alliances and structures. Actually we identified over fifty such hidden sources. None are found in traditional accounting systems.'

As such a number of values was unmanageable, Edvinson came up with a definition of intellectual capital that had two dimensions: human capital and structural capital. These were further refined to develop the map of intellectual capital (Skyrme and Amidon 1997:165).

Figure 2 Skandia Navigator (Source: Skyrme and Amidon 1997:143)

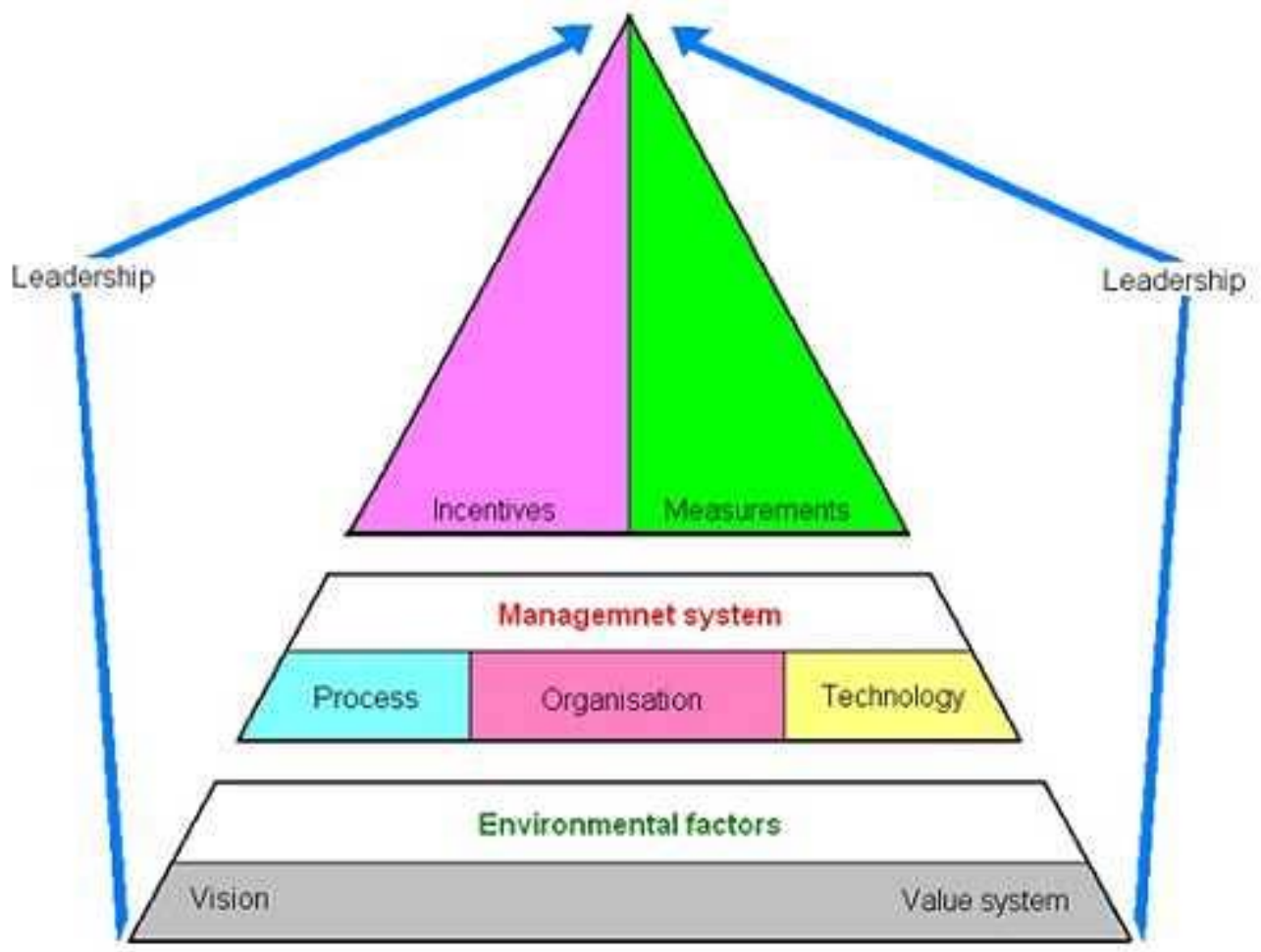


The Navigator framework has at its top end a series of measures relating to the financial focus (see Figure 2). But it also has 'below the line' measures of intellectual capital. These involve four areas and two dimensions. These non-financial measures are:

- Customer focus, which quantifies how the organization is to look to its customers

- Process focus, which quantifies key aspects of the organization's process performance

- Renewal and development, which quantifies what is being done to renew and develop the intellectual asset base

- Human focus, the 'virtual' binding force of customer, process, renewal and development and finance.

\subsection{Dow intellectual asset management model}

The Dow Chemical Company has a very clear vision of the future: 'To maximise the business value of intellectual assets.' Therefore, they developed a comprehensive framework to manage every phase of the knowledge process, along with a set of models and techniques to assist with the valuation and measurement of capital assets. This intellectual asset management model consists of six steps (Figure 3):

- Business strategy determines the role of knowledge in the business and includes an assessment of alignment of intellectual assets with goals for product and market development.

- Competitor assessment determines the technologies and intellectual assets that the competitors have that impact on the business strategy and knowledge assets.

- Asset classification determines the portfolio of intellectual assets, identifies the owners, what assets are used, what will be used and where it belongs.

- Valuation assesses the business value of the intangible assets.

- Investment enhances the value of these assets and attends to the gaps that need filling to thwart competitors.

- Portfolio management assembles individual assets into a comprehensive intellectual asset portfolio, which then becomes the starting point for a further cycle of the process (Skyrme and Amidon 1997:101).

Figure 3 Dow's intellectual asset management model (Source: Skyrme and Amidon 1997:102)

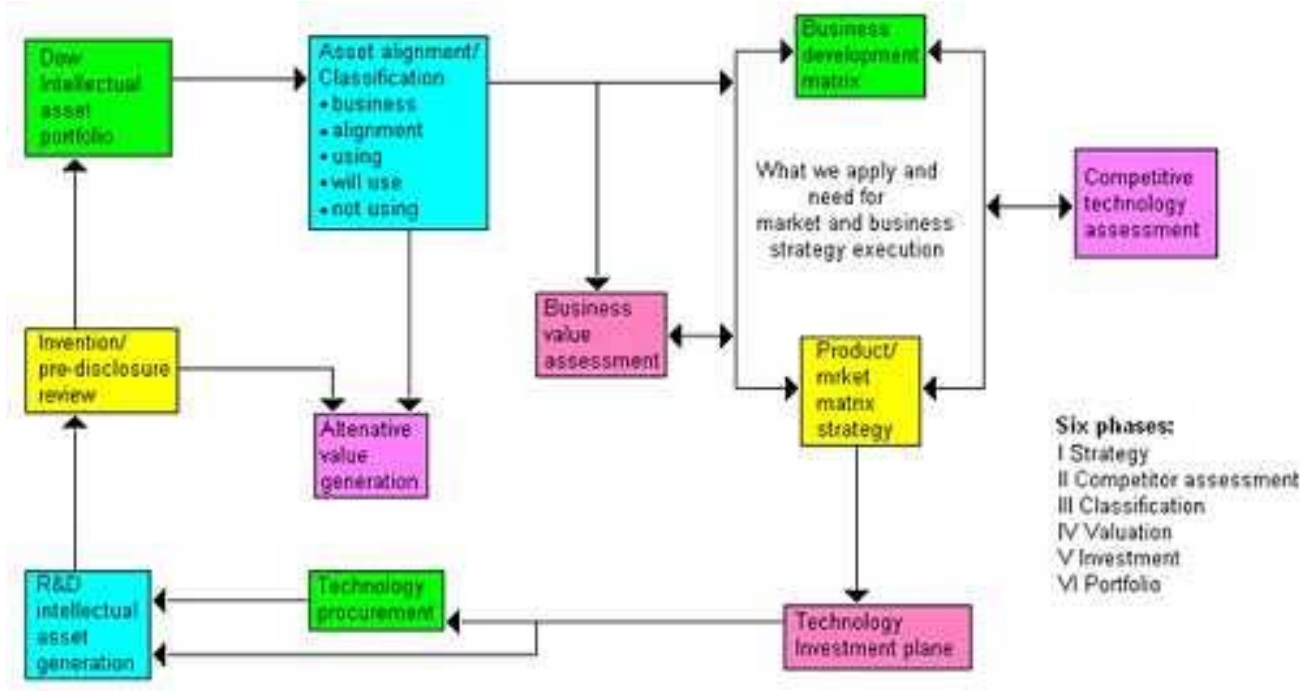


Price-Waterhouse uses a three-level framework for guiding clients' knowledge management activities. The three levels are:

- Business and value contribution of knowledge: Management determines where and how the organization generates value for the customer through its knowledge

- Knowledge management processes: The knowledge cycle of creating and sharing, and where and how to apply

- Knowledge network and infrastructure: The technical and content infrastructure (Skyrme and Amidon 1997:91).

\subsection{Intellectual capital management framework}

As an intellectual capital-intensive company, knowledge management lies at the core of IBM's business. The knowledge management programme at IBM is called intellectual capital management. To remain competitive, the company must become more agile, innovative and responsive to the demands of customers. Therefore the three fundamentals of their knowledge management effort are: teamwork, execution and winning (Huang 1998:576).

Utilizing the intellectual capital of professionals is a critical initiative at IBM and the intellectual capital management effort is the foundation of knowledge sharing and reuse within the corporation. Intellectual capital management is being implemented through processes based on a management framework derived from best practices assessment and learning conducted by IBM.

This framework serves as the foundation for the intellectual capital management programme. It has three levels, with leadership shown as driving the links between them (See Figure 4.) The framework is used to promote IBM's knowledge management activities internally, and is portrayed as a 'hub' surrounding the 'essential building blocks for the knowledge-based enterprise.' These building blocks include enabling technologies and applications, such as learning networks and decision rooms (Skyrme and Amidon 1997:91)

Figure 4 Intellectual capital management framework (Source: Huang 1997:151)

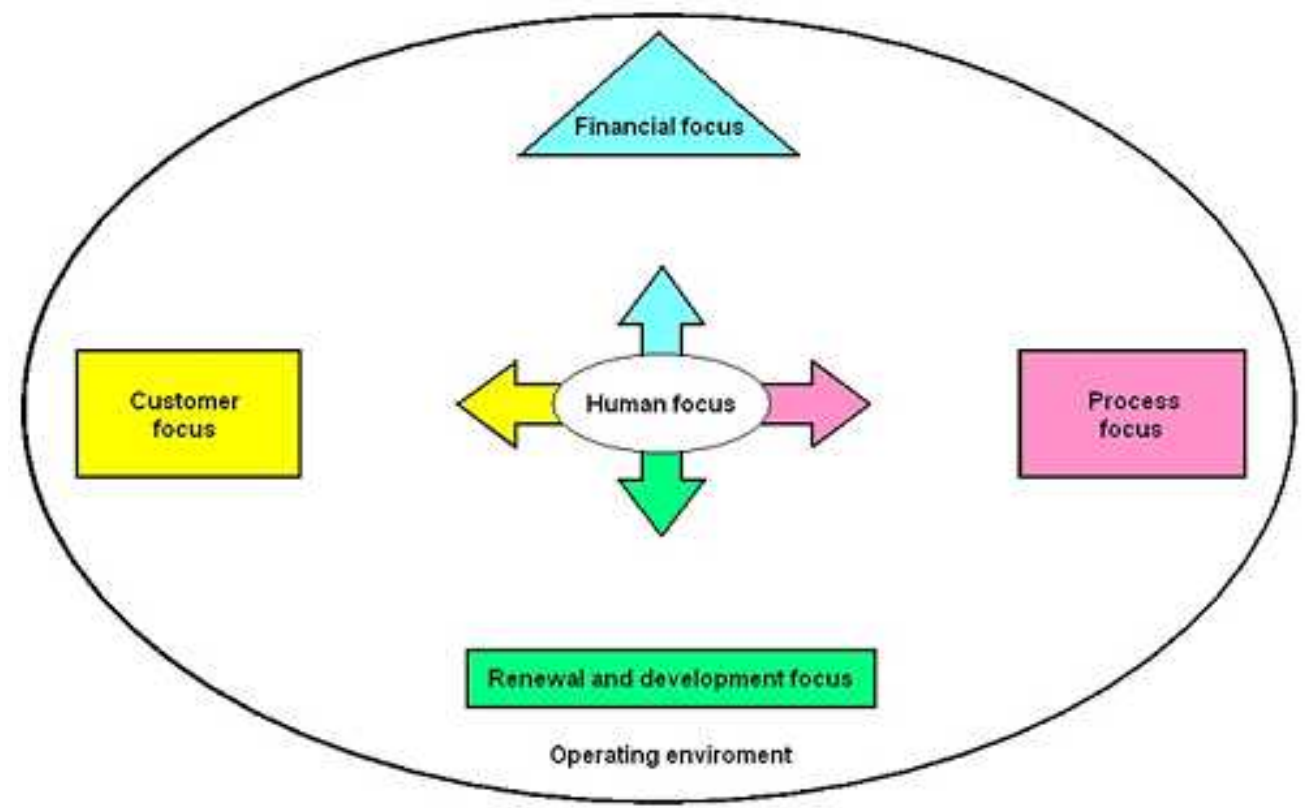

The intellectual capital management framework incorporates: 
- Vision/strategy/values that promote sharing and reusing knowledge and assets. These elements reflect consistent themes that promote internal alignment and present a clear, unified presence to support the customer. Everyone strives toward the same goal with a singularity of purpose and one set of principles.

- Processes for efficiently gathering, evaluating, structuring and distributing intellectual capital. Standardization and methodology provide systematic, efficient and effective capture and retrieval of information while fostering a sense of 'one firm, one face' globally. Consistent standards and methodology enable reuse by any team, any group, anywhere in the world.

- Communities of professionals with common interests, defined roles and responsibilities. An informal network structure is most conducive to knowledge sharing and enhancement. These networks create a sense of fraternity and bonding. Each provides a natural vehicle for obtaining insights, sharing experiences and optimizing reuse. Institutionalizing these informal network structures minimizes external management interference while it maximizes internal teams' freedom to act.

- Technology that enables company-wide collaboration and sharing. Information technology plays a key role in building a knowledge infrastructure that can be deployed and accessed globally. In a world where what one can earn depends on what one can learn, the successful firms are those that are leaders in utilizing technology to support life-long learning and training for its professionals and to reach its customers and business partners.

- Incentives/measurements to encourage intellectual capital contribution and reuse, and to monitor knowledge usage and its value to the organization. Additional bonuses and recognition by peers are provided for practitioners who have submitted and/or reused intellectual capital. Changes have been made to the annual performance measurement process, whereby practitioners are measured against their achievement of goals during the year, to include intellectual capital contribution (Huang 1999).

\subsection{Intangible assets monitor framework}

When a company invests in material assets such as machines, or computers, the money is paid out of liquid funds, and a corresponding amount is booked as an asset on the balance sheet under a heading such as 'machinery'. In accounting terms, there has been a negative cash flow, but no expenditure. The cost is incurred gradually, as the asset is depreciated.

When a company invests in an intangible asset such as a research programme or an entrance to a new customer segment, it is not generally permitted to record the value of the research as an asset on the balance sheet. The investment thus appears both as a negative cash flow and as a cost item. Both types of investment are inspired by the same motive; to achieve higher profitability in the long term, by sacrificing cash flow in the short term. The difference in accounting treatment, however, is very confusing and is made more so by the fact that the 'cost' of intangible investments can take forms other than direct payments from cash reserves. It may take the form, for example, of accepting an assignment that yields little cash revenue but has great publicity value, or seems likely to enhance competence. Here again the intangible asset is 'financed' by 'invisible' equity.

Expenditure on research and development (R\&D) generates value, which is clearly owned by the company, so it is reasonable to regard such expenditure as investment. True, the economic value is uncertain, but the same can be said of any investment, including the value of city centre office buildings, as many investors have learned the hard way in recent years. However, cash outlays for knowledge acquisition are not always intangible 'assets'. Many commentators insist that training and education costs should be viewed as investments, but to whom or what does the value created by such investment accrue? When individuals pay for their own education, they are investing in their own personal capital, but when the company 
pays for education, the link between payer and asset is broken. The company is paying for an asset it will not own. Individual competence is 'owned' by individuals and not companies. Therefore, from the company's point of view, money spent on educating employees should be treated as a cost, not an investment.

To measure these intangibles and intellectual capital, Sveiby developed the intangible assets monitor (Figure 5).

Figure 5 Intangible assets monitor (Source: Sveiby 1998b)

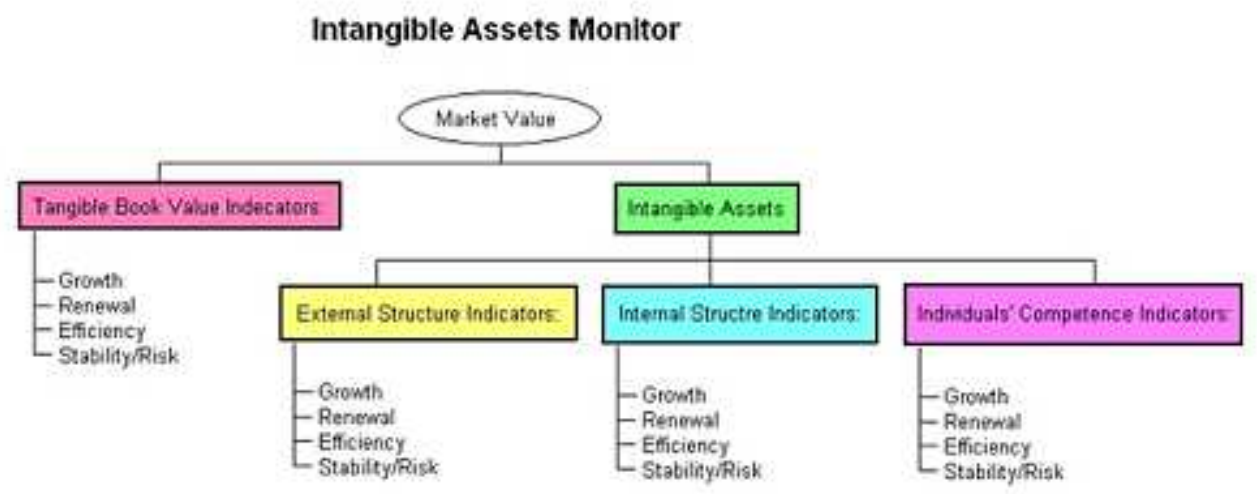

In this framework, the three different indicators that form part of intangible assets may be described as follows:

- External structure, which consists of relationships with customers and suppliers, brand names, trademarks and reputation, or 'image'. Some of these may be considered legal property, but the bond is not as strong as in the case of internal assets because investments in them cannot be made with the same degree of confidence. The value of such assets is primarily influenced by how well the company solves its customers' problems, and there is always an element of uncertainty here. Reputations and relationships may be good or bad, and may change over time. The external structure is not particularly liquid, and unlike the material assets, they may or may not be legally owned by the company. The economic value of a customer relation is no more 'invisible' than the market value of a house. The reason why the value of a relation seems invisible today is because it does not have a generally accepted definition and it is not measured according to a standard. But these drawbacks do not mean that it is impossible or unnecessary to measure it, only that comparisons between companies and over time are difficult to make.

- Internal structure, which consists of a wide range of patents, concepts, models, and computer and administrative systems. These are created by the employees and are thus generally 'owned' by the enterprise. Sometimes they are acquired from elsewhere. Decisions to develop or invest in such assets may be made with some degree of confidence, because the work is done in-house, or bought from outside. Also, the informal enterprise, the internal networks, the 'culture' or the 'spirit' belongs to the internal structure. The internal structure and the people together constitute what is generally called 'the enterprise'.

- Individual competence, which refers to employees' capacity to act in various situations. It includes skill, education, experience, values and social skills. People are the only true agents in business; all assets and structures, albeit tangible physical products or intangible relations are the result of human action and depend ultimately on people for their continued existence. Competence cannot be owned by anyone or anything but the person who possesses it because, when all is said and done, employees are voluntary members of the enterprise. However, a case can be made for including competence in 
the balance sheet, because it is impossible to conceive of an enterprise without people. People tend to be loyal, if they are treated fairly and feel a sense of shared responsibility. That is why companies are generally willing to pay some kind of compensation to those who retire, or have to be laid off. This kind of compensation varies from country to country, but often takes the form of redundancy pay, umbrella agreements ('golden parachutes') and pensions. Although such commitments are not recorded as liabilities in the balance sheet, they can be seen as pledges or commitments, similar to leasing or rental contracts, and thus a form of invisible financing of employee competence.

\section{Conclusion}

Businesses practicing knowledge management is a 90s phenomenon. As the shape of the knowledge economy becomes more obvious, so the need for systematic practices that capture and disseminate organizational knowledge that can be used for competitive advantage will increase. Knowledge management will not come about spontaneously and neither will it thrive without sustained human intervention. Leadership is vital in this regard.

Knowledge leadership posits the management of organizational knowledge as a core strategy that helps achieve corporate strategic goals (Skyrme and Amidon 1997). Knowledge must support the purpose of an enterprise in such a way that every operational level is enriched by the organization of its knowledge requirements and its products. In this way the rich tapestry that is corporate knowledge is crafted and converted into capital that can assist in the development of business advantage.

Knowledge management requires a knowledge champion with the vision to motivate people within organizations to engage in knowledge sharing practices. Interpersonal and communication skills are particularly important knowledge management skills, as are emotional maturity, enthusiasm and the ability to create networks both internally and externally. To succeed, the knowledge champion must have the backing of the CEO and top management. Without resources and top-down support there is no chance of fostering enterprise-wide mobilization. The CIO's main role is to ensure that the technology and information technology infrastructure necessary for the knowledge management programme is in place and functioning. The CIO must also ensure the strategic alignment of technology and the enterprise's objectives. The chief knowledge officer's (CKO's) role is to act as a knowledge leader and ensure that the structures, networks and culture that make knowledge management possible are implemented and fostered. While appreciating the value of technology, the CKO is more concerned with the human side of knowledge management processes. He or she is primarily a facilitator and a motivator.

The new emphasis on knowledge management has led to the rise of new knowledge roles that facilitate the acquisition, classification, editing, packaging and distribution of knowledge. As knowledge management as a discipline matures, more roles are sure to follow.

\section{References}

Amidon, D.M. 2000. Virtual chief knowledge officer (CKO): leading through strategic conversations. [Online]. Available WWW: 
Barclay, R.O. 2003. Leading the knowledge enterprise - CIOs, CLOs, CKOs and beyond. [Online]. Available WWW: http://www.ktic.com/resource/km3/Leading\%20the\% 20knowledge\%20

enterprise\%20andmdash\%3B\%20CIOs,\%20CLOs,\%20CKOs,\%20and\%20beyond.htm. (Accessed 26 May 2003).

Bonner, D. 2000. Enter the chief knowledge officer. [Online]. Available WWW: http://www.findarticles.com/cf_0/m4467/2_54/59949725/print.jhtml. (Accessed 25 May 2003).

Davenport, T. 1996. Knowledge roles: the CKO and beyond. [Online]. Available WWW: http://www.cio.com/archive/040196_davenport_content.html. (Accessed 26 May 2003).

Davenport, T. 1999. Coming soon: the CKO. [Online]. Available WWW:

http://www.informationweek.com/509/knowledge leader.htm.(Accessed 20 May 2002).

Duffy, D. 1998. Knowledge champions. [Online]. Available WWW:

http://www.cio.com/archive/enterprise/111598_ic_content.html. (Accessed 25 May 2003).

Earl, M.J. 1999. What is a chief knowledge officer? [Online]. Available WWW:

http://www.findarticles.com/cf_0/m4385/2_40/55937365/print.jhtml. (Accessed 25 May 2003).

Huang, K-T. 1997. Capitalizing collective knowledge for winning, execution and teamwork. Journal of Knowledge Management 1(2):149-156.

Huang, K-T. 1998. Capitalizing on intellectual assets. IBM Systems Journal 37(4):570-583.

Huang, K-T. 1999. Capitalizing collective knowledge for winning, execution and teamwork. [Online]. Available WWW: http://www.ibm.com/services/articles/intelcap.html. (Accessed 25 February 1999).

Nonaka, I. and Takeuchi, H. 1995. The knowledge creating company: how Japanese companies create the dynamics of innovation. New York: Oxford University Press.

Rubin Systems Inc. 1998. Scandia's business navigator. [Online]. Available WWW: http://www.hrubin.com/headline/skandia.html. (Accessed 30 July 2002).

Skyrme, D.J. and Amidon, D.M. 1997. Creating the knowledge-based business. London: Business Intelligence.

Sveiby, K. 1998. Measuring intangibles and intellectual capital - an emerging first standard. [Online]. Available WWW:

http://www.sveiby.com/articles/EmergingStandard.html. (Accessed 1 June 2003).

\section{Disclaimer}

Articles published in SAJIM are the opinions of the authors and do not necessarily reflect the opinion of the Editor, Board, Publisher, Webmaster or the Rand Afrikaans University. The user hereby waives any claim he/she/they may have or acquire against the publisher, its suppliers, licensees and sub licensees and indemnifies all said persons from any 
claims, lawsuits, proceedings, costs, special, incidental, consequential or indirect damages, including damages for loss of profits, loss of business or downtime arising out of or relating to the user's use of the Website.

ISSN 1560-683X

Published by InterWord Communications for the Centre for Research in Web-based Applications, Rand Afrikaans University 